\title{
Antibacterial, Antioxidant and Cytotoxic Properties of Crinum asiaticum Bulb Extract
}

\author{
Md. Atiar Rahman ${ }^{1 *}$, Rumana Sharmin ${ }^{1}$, Md. Nazim Uddin ${ }^{1}$, Md.Sohel Rana ${ }^{1}$ and Nazim Uddin Ahmed ${ }^{2}$ \\ ${ }^{I}$ Department of Biochemistry and Molecular Biology, University of Chittagong, Chittagong-4331, Bangladesh. Bangladesh Council for Scientific and \\ Industrial Research (BCSIR), Chittagong, Bangladesh.
}

(Received 17 December 2010; Accepted 9 April 2011)

\begin{abstract}
Antibacterial effect of Crinum asiaticum bulb extract (1mg/disc) was tested on four Gram- positive and six Gram-negative bacteria by disc diffusion method using kanamycin (30 ìg/disc) as standard antibiotic disc. The bulb extract $(250-1000 \mathrm{mg} /$ disc) showed significant zone of inhibition against all Gram-positive and Gram-negative bacteria ranging from $12-14 \mathrm{~mm}$ in diameter. Antioxidant potential of the same extract was evaluated by 2,2-diphenyl-1-picrylhydrazyl (DPPH) scavenging method. The extract showed remarkable free radical scavenging effect $(95.96 \%)$ providing the $\mathrm{IC}_{50}$ value of 5.62 for the bulb extract and 5.46 for ascorbic acid (standard antioxidant) at the concentration of $1000 \mathrm{ig} / \mathrm{ml}$. The bulb extract was found to be $\left(\mathrm{LC}_{50}\right.$ value 94.06 $\mu \mathrm{g} / \mathrm{ml}$ ) in Brine-Shrimp lethality test.
\end{abstract}

Key words: Crinum asiaticum; DPPH; Kanamycin; Scavenging; Gallic acid.

\section{Introduction}

Crinum asiaticum locally known as Bara kanur, is an evergreen herb that is widely distributed in China, Hongkong, India, Srilanka, Myanmar, Thailand, Malaysia and Mainland Japan ${ }^{1-3}$. It is also found in hilly areas of Bangladesh especially in Chittagong. It has been used by the tribes of Chittagong Hill tracts for their treatment of pain, swelling carbuncle, piles, earache, arthritis, skin disease, cold and cough disorders, vomiting, worms infestation, disuria, polyuria, bowel complains, throat disorder, colic, dyscrasia, flatulence, fever ${ }^{1-3}$. Traditional uses of the leaves and roots of this plant include emetic, diaphoretic and purgative. Leaves of smeared $C$. asiaticum with warmed castor oil are useful remedies for repelling inflammations and swellings at the end of toes and fingers. The plant is also used to treat inflammed joints and sprains. Slightly warmed juice of the leaves, mixed with a little salt, has been used for earache and other ear complaints. Roasted bulb is used as rubefacient in rheumatism. Bruised leaves of this plant act as an efficient insect repellent ${ }^{1-3}$.

Although, the traditional uses of the C. asiaticum are now popularized, however, very few scientific evaluations of this plant have been documented so far. This study was, therefore, taken to test the antimicrobial, antioxidant and cytotoxic activity of $C$. asiaticum bulb extract.

\section{Materials and Methods}

\section{Collection of Plant}

The bulbs of C. asiaticum were collected from Chittagong Hill tracts, Bangladesh, in the month of January 2009. The plant was taxonomically identified and authenticated by Dr. Shaikh Boktear Uddin, Assistant Professor, Department of Botany, University of Chittagong. The voucher specimen is preserved in Bangladesh National Herbarium under the plant accession no. 34545.

\section{Preparation of Plant Extract}

The fresh bulbs of C. asiaticum (Syn: Crinum amabile) were minced into small pieces, air dried at room temperature for about 10 days, ground into powder (536.46g ) and extracted with methanol (99\% Anal-R), being macerated at room temperature $(23 \pm 5)^{\circ} \mathrm{C}$ for 15 days with occasional stirring. Methanol was filtered off through a cotton plug and concentrated under reduced pressure below $50^{\circ} \mathrm{C}$ through rotatory vaccum evaporator (RE200 Sterling, UK). The concentrated bulb extract $(35 \mathrm{~g}$, yield $6.5 \% \mathrm{w} / \mathrm{w})$ was stored at $4^{\circ} \mathrm{C}$.

\section{Bacterial strains and antibiotic disc}

Four Gram-positive (Bacillus cereus, Bacillus subtilis, Bacillus megaterium and Staphylococcus aureus) and six Gram-negative (Escherichia coli, Salmonela typhi, Salmnela paratyphi, Pseudomonous sp (I), Pseudomonous sp (II) and Shigella sonnei) bacterial strains were used in the present study (Table 1). All the strains were collected from the Department of Microbiology, University of Chittagong. All the strains were grown in Mueller-Hinton agar medium. Kanamycin (30ìg/disc, Oxoid, England) was used as a standard antibiotic disc.

Preparation of discs

The discs of about $4 \mathrm{~mm}$ in diameter were cut by punching machine from Whatman No.1 filter paper. The discs were taken in a petri dish and sterilized by autoclaving, dried in oven at $180^{\circ} \mathrm{C}$.

*Corresponding author:

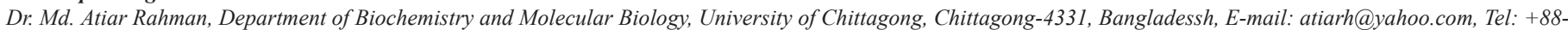
01711709084, Fax: +88-031-726310, Ex-433 


\section{Preparation of extract solution}

A measured amount of $C$. asiaticum bulb extract was dissolved in definite volumes of methanol to give solution of known concentration $(100 \mu \mathrm{g} / \mu \mathrm{l})$. Methanol was chosen as solvent because the crude extract is completely dissolved in methanol and it has no inhibitory effect on the cultures.

\section{Assay for Antibacterial Activity}

Antibacterial activity of plant extract was determined by disc diffusion method ${ }^{4}$. Discs (4 mm in diameter) impregnated in known amount of test substances (500 ìg/discs) were placed on MuellerHinton agar medium uniformly seeded with the test organisms and kept at low temperature $\left(4^{\circ} \mathrm{C}\right)$ for two to four hours to allow maximum diffusion of compound. The diffusion occurred according to the physical law that controls the diffusion of molecules through agar gel ${ }^{5}$. The plates were then incubated at $37^{\circ} \mathrm{C}$ for 24 hours to allow maximum growth of the microorganisms. Antibacterial effects were determined by measuring the diameter with a transparent scale in millimeter based on appearance of the clear zones of inhibition on the discs. The results were compared with the control antibiotic, Kanamycin.

\section{Assay for Antioxidant Activity}

The antioxidant activity of $C$. asiaticum extract was tested on the basis of its stable 2,2-diphenyl-1-picrylhydrazyl (DPPH) free radical scavenging effect according to established procedure ${ }^{6,7}$ using ascorbic acid as a positive control (BDH, England). Ascorbic acid solution ( $1 \mathrm{ml})$ and different concentrations (10, 50, 100, 200, 400,600 and $800 \mathrm{ig} / \mathrm{ml}$ in methanol) of $1 \mathrm{ml}$ of $C$. asiaticum solution were mixed with $3 \mathrm{ml}$ of $0.4 \mathrm{mM}$ DPPH solution. The mixtures were kept in dark for 30 minutes to measure the absorbance at $517 \mathrm{~nm}$ using a UV-Visible Spectrophotometer (Cintra, Australia). Lower absorbance of the reaction mixture indicated higher free radicalscavenging activity. The procedure also involves the degree of decolorization of DPPH from purple to yellow indicating the scavenging efficiency of the extract. The scavenging activity against DPPH was calculated by the following equation:

$$
\text { Scavenging activity }(\%)=[(\mathrm{A}-\mathrm{B}) / \mathrm{A}] \times 100
$$

Where A was the absorbance of control (DPPH solution without the sample), B was the absorbance of DPPH solution in the presence of the sample (extract/ascorbic acid). Percent (\%) of scavenging activity was plotted against log concentration and from the graph $\mathrm{IC}_{50}$ (Inhibition concentration 50) value was calculated by linear regression analysis.

\section{Assay for Cytotoxicity}

Cytotoxic activity of plant extract was determined by Brine-Shrimp lethality test $^{8}$. Shrimp eggs were added to the artificial "sea water" (25g salt/ liter water) in the larger compartment of an unequally divided tank which was darkened by covering it with Aluminum foil $^{9}$. The chamber was kept under illumination using a table lamp for $48 \mathrm{~h}$ for the eggs to hatch into shrimp larvae. The illuminated compartment attracts shrimp larvae (nauplii) through perforations in the dam. Twenty shrimps larvae were added to $5 \mathrm{ml}$ of sea water in 5 test tubes and 200,100, 50, 25, $10 \mu \mathrm{g} / \mathrm{ml}$ solutions of extracts, prepared from $500 \mathrm{mg}$ of crude through serial dilution, were added to these test tubes. Each concentration was tested in triplicate. A control containing $5 \mathrm{ml}$ of DMSO solvent was used for each solvent. The test tubes were maintained under illumination. After 24 hours have elapsed, survivors were counted with the aid of a $3 \mathrm{X}$ magnifying glass. From the $\%$ lethality of brine shrimp, the probits (probability unit) were calculated for each concentration by using "BioStat-2007" software. Probits were then plotted against corresponding log concentration of bulb extract to get $\mathrm{LC}_{50}$ (lethal concentration 50) value through regression analysis.

\section{Qualitative Phytochemical Tests}

Alkaloid test: Crude ethanol extract of $C$. asiaticum bulb was subjected to analyze for the occurrence and existence of alkaloid in the extract. Extract $(0.5 \mathrm{~g})$ was neutralized by adding 1 or 2 drop of dilute $\mathrm{H}_{2} \mathrm{SO}_{4}$. The resulting solution was treated with a very small amount of Mayer's reagent (potassiomercuric iodide solution), Wagner's reagent (Iodopotassium iodide) and Hager's reagent $(1 \% \text { picric acid solution })^{10}$. The color of precipitates formed in each case was noted (Table 4).

Flavonoid test: A small amount of the extract and few drops of concentrated hydrochloric acid were mixed and immediate color development was observed minutely ${ }^{11}$.

\section{Results and Discussion}

The methanol extract of $C$. asiaticum were found to be active against all tested organisms except $B$. cereus, Pseudomonas $s p$ and Shigella sonnei with lower concentration $(250 \mathrm{mg} /$ disc $)$ of plant extract. The zone of inhibition for the extract of different concentrations against four Gram-positive and six Gram-negative bacterial strains are summarized in Table 1. The Kanamycin, the antibiotic control showed pronounced antibacterial activity against all the test organisms. It is clear that extract showed antimicrobial activity in a dose-dependent manner where the extract concentration $(1000 \mathrm{mg} /$ disc $)$ showed the largest zone of inhibition to Gram-positive bacteria. However, the zone inhibitory effect of the same concentration was lower to Gram-negative organisms.

Successful prediction of botanical compounds from plant material is largely dependent on the type of solvent used in the extraction procedure. Traditional medicinal plants are used primarily water as the solvent but in our studies we found that plant extracts in organic solvent (methanol) provided more consistent antimicrobial activity compared to those extracted in water. These observations can be rationalized in terms of the polarity of the compounds being extracted by each solvent and in addition to their intrinsic bioactivity. ${ }^{12}$ Methanolic extracts of plants generally possess terpines and phenolics, which are reported by different workers as antimicrobial compounds ${ }^{13-14}$. Phytochemicals exert their antimicrobial activity through different mechanisms, tannins for example act by iron deprivation, hydrogen bounding or non specific interactions with vital proteins such as enzymes ${ }^{15}$. Some 
Table 1. In vitro antibacterial activity of $C$. asiaticum bulb extract

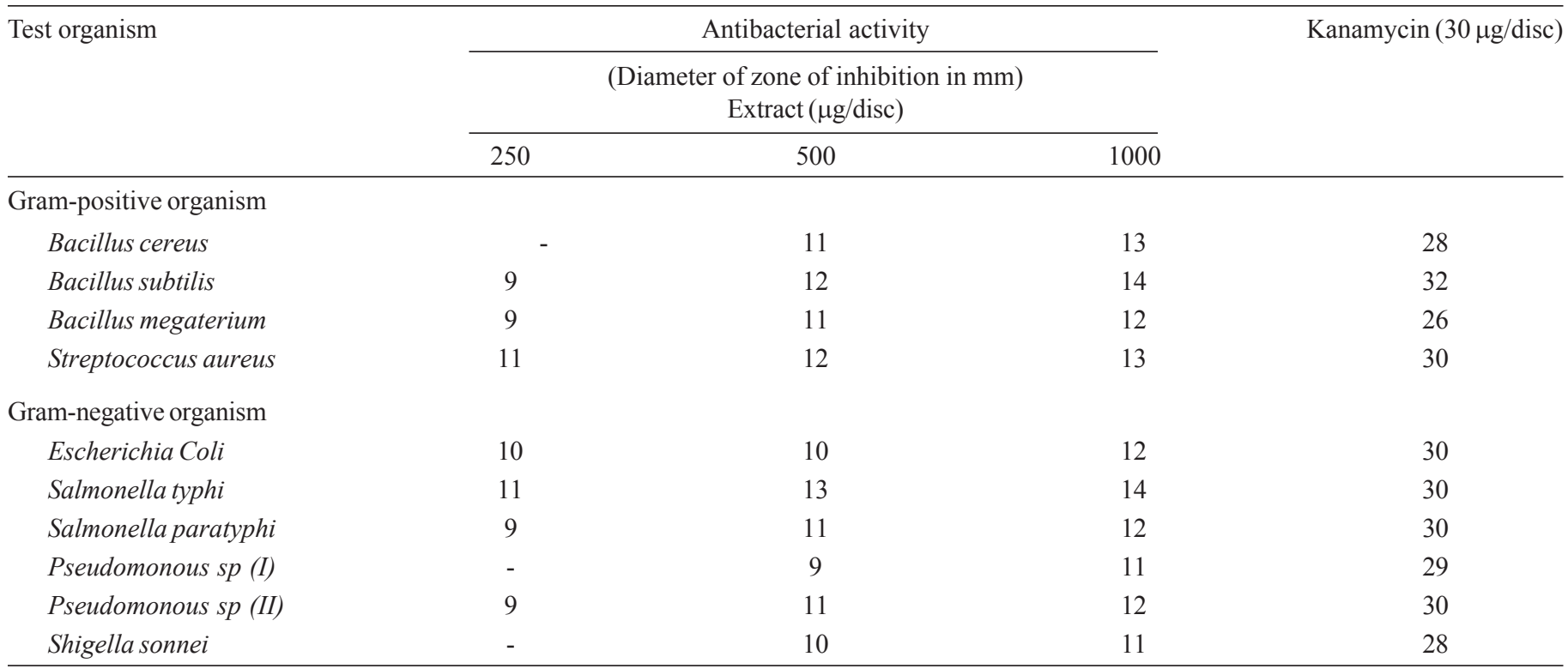

alkaloids like indoloquinoline alkaloid and cryptolepine ${ }^{16}$ cause cell lysis and morphological changes of $S$. aureus, but the antimicrobial effects of the alkaloid may be through another mechanism, since these compounds are known to be a DNA intercalator and an inhibitor of DNA synthesis through topoisomerase inhibition ${ }^{17}$. Therefore, the phytochemical differences between different plants cause the difference in the antibacterial activities of their extract's composition ${ }^{12,18}$. A phytochemical investigation of the bulbs of Crinum asiaticum $L$. var. sinicum Baker resulted in the isolation of two new alkaloids, asiaticumines A and B (1 and 2, resp.), together with 21 known compounds, including nine alkaloids, four amides, five phenolic compounds, and three flavonoids. All 23 compounds were isolated for the first time from Crinum asiaticum $\mathrm{L}$. var. sinicum Baker ${ }^{19}$. However, presence of such alkaloids and flavonoids in our phytochemical screening (Table 4) supports our observations that the antibacterial activity exerted by the extract is due to either of these secondary metabolites.

DPPH (2,2-diphenyl-1-picrylhydrazyl) free radical scavenging activity of the $C$. asiaticum bulb extract and ascorbic acid is depicted in Table 2. Both ascorbic acid and bulb extract showed a dose dependent activity. However, bulb extract showed very strong DPPH free radical scavenging effect compared to ascorbic acid. Bulb extract and ascorbic acid promoted the highest scavenging activity $95.96 \%$ and $98.66 \%$, respectively, at the concentration of $1000 \mathrm{ig} / \mathrm{ml}$ (Table 2). Regression analysis from the plot of (\%) scavenging activity versus log concentration showed the $\mathrm{IC}_{50}$ value of ascorbic acid $(5.46 \mathrm{ig} / \mathrm{ml})$ and bulb extract $(5.62 \mathrm{ig} / \mathrm{ml})$, respectively.

This method has developed by utilizing the stable DPPH radical to determine the antioxidant activity of natural products ${ }^{20}$. The odd electron in the DPPH free radical gives a purple color with maximum absorption at $517 \mathrm{~nm}$. The color turns to yellow as the molar absorptivity of the DPPH radical reduces from 9660 to 1640 when the odd electron of DPPH radical becomes paired with hydrogen from a free radical scavenging antioxidant to form the reduced DPPH-H. The resulting decolorization is stoichiometric with respect to number of electrons captured. $\mathrm{IC}_{50}$ value denotes the concentration of sample required to scavenge $50 \%$ of the DPPH free radical $^{21}$.

Table 2. DPPH free radical scavenging activity of C. asiaticum bulb extract and ascorbic acid

\begin{tabular}{|c|c|c|c|c|c|c|c|}
\hline \multirow{2}{*}{$\begin{array}{l}\text { Sample } \\
\operatorname{con}^{\mathrm{n}}(\mu \mathrm{g} / \mathrm{ml})\end{array}$} & \multirow[t]{2}{*}{$\log \operatorname{con}^{n}$} & \multicolumn{2}{|c|}{ Absorbance } & \multicolumn{2}{|c|}{$\%$ Scavenging activity } & \multicolumn{2}{|c|}{$\mathrm{IC}_{50}(\mu \mathrm{g} / \mathrm{ml})$} \\
\hline & & Bulb Extract & Ascorbic acid & Bulb Extract & Ascorbic acid & Bulb Extract & Ascorbic acid \\
\hline Control & - & 0.8146 & 0.8146 & - & - & & \\
\hline 50 & 1.7 & 0.2893 & 0.2149 & 64.49 & 73.62 & & \\
\hline 100 & 2 & 0.2645 & 0.12815 & 67.53 & 84.27 & 5.62 & 5.46 \\
\hline 200 & 2.3 & 0.215 & 0.0804 & 73.61 & 90.13 & & \\
\hline 600 & 2.78 & 0.1135 & 0.0446 & 86.07 & 94.52 & & \\
\hline 800 & 2.9 & 0.0619 & 0.0239 & 92.40 & 97.07 & & \\
\hline 1000 & 3 & 0.0329 & 0.0109 & 95.96 & 98.66 & & \\
\hline
\end{tabular}


Table 3. Brine shrimp lethality for the methanol extract of C. asiaticum bulb

\begin{tabular}{|c|c|c|c|c|c|c|c|}
\hline Dose( $1 \mathrm{~g} / \mathrm{ml})$ & Log dose & Total(n) & Alive & Death & $\%$ Lethality & Actual \%* & Probit $^{\mathrm{a}}$ \\
\hline 10 & 1.000 & 20 & 20 & 0 & 0.0 & 1.25 & 0.994 \\
\hline 25 & 1.398 & 20 & 19 & 1 & 5.0 & 5 & 3.866 \\
\hline 50 & 1.699 & 20 & 17 & 3 & 15.0 & 15 & 3.964 \\
\hline 100 & 2.000 & 20 & 13 & 7 & 35.0 & 35 & 4.622 \\
\hline 200 & 2.301 & 20 & 0 & 20 & 100.0 & 98.75 & 6.838 \\
\hline
\end{tabular}

a probit were calculated using statistical software "Biostat 2007"

*Actual $\%=$ Actual formulas ( $\mathrm{n}$ is the number of animals in a group): For the $0 \%$ dead, $100(0.25 / \mathrm{n})$, for the $100 \%$ dead, 100 (n- 0.25$) / \mathrm{n}$

The closeness of $\mathrm{IC}_{50}$ value of $C$. asiaticum bulb extract (5.62 ìg/ $\mathrm{ml})$ with that of ascorbic acid $(5.46 \mathrm{ig} / \mathrm{ml})$ indicates the similar efficiency of extract, to neutralize free radicals, is as like as that of ascorbic acid (Fig. 1). Different research suggests that most of the plant extracts showing antioxidant activity are due to the presence of phenolic compounds ${ }^{22-23}$. Flavonoids are a group of phytochemicals found in varying amounts in foods and medicinal plants which have been shown to exert potent antioxidant activity against the superoxide radical. Antioxidant activity of flavonoids (Table 4) is due to their redox properties which allow them to act

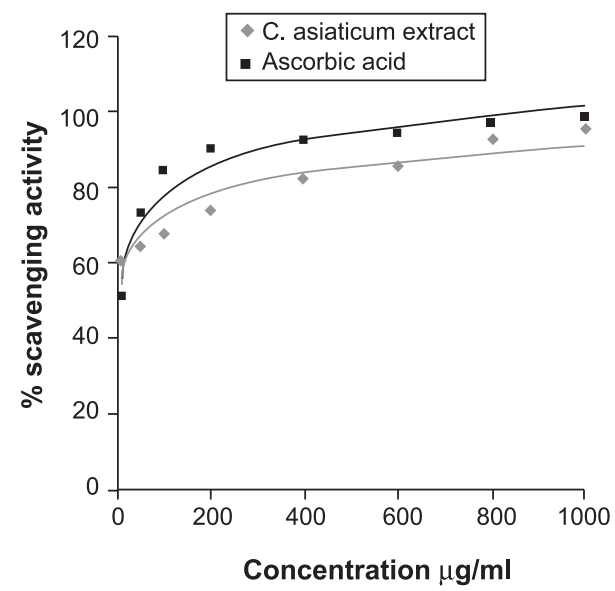

Figure 1. Comparative \% scavenging activity of C. asiaticum bulb extract and ascorbic acid.

Table 4. Observation on qualitative phytochemical screening

\begin{tabular}{lccc}
\hline Name of the test & Reagent & $\begin{array}{c}\text { Change of colors } \\
\text { Mayer's } \\
\text { reagent }\end{array}$ & $\begin{array}{c}\text { White or } \\
\text { creamy white } \\
\text { precipitate }\end{array}$ \\
Alkaloid test & $\begin{array}{c}\text { Wagner's } \\
\text { reagent }\end{array}$ & $\begin{array}{c}\text { Brown or } \\
\text { deep brown } \\
\text { precipitate }\end{array}$ & ++ \\
& $\begin{array}{c}\text { Hager's } \\
\text { reagent }\end{array}$ & $\begin{array}{c}\text { Yellow } \\
\text { crystalline } \\
\text { precipitate }\end{array}$ & ++ \\
& & $\begin{array}{c}\text { Development } \\
\text { of color }\end{array}$ & ++ \\
Flavonoid & Conc. HCl & & ++ \\
\hline
\end{tabular}

"++" indicates the presence. as reducing agents, hydrogen donors and singlet oxygen quencher. In addition, they have metal chelating potentials ${ }^{24}$. The phenolic compounds, identified in the extract, might contribute to the antioxidant activity of $C$. asiaticum bulb extract.

Bulb extract showed lethality in a dose dependent manner in Brine-shrimp test. Percent mortality of brine shrimp observed at $10,25,50,100,200 \mu \mathrm{g} / \mathrm{ml}$ of extract were $1.25,5,15,35$ and $98.75 \%$ (Table 3). $\mathrm{LC}_{50}$ value of $C$. asiaticum bulb extract was found $94.06 \mu \mathrm{g} / \mathrm{ml}$ at $95 \%$ confidence limit where the lower and upper limits were 75.29 and $119.17 \mu \mathrm{g} / \mathrm{ml}$ (Fig. 2).

Brine shrimp lethality assay, a general bioassay ${ }^{8}$, is an indication of cytotoxicity, antibacterial activities, pesticidal effects and various pharmacologic actions ${ }^{25}$. In this study, the $\mathrm{LC}_{50}$ value of the extract was found very significant $(94.06 \mathrm{ig} / \mathrm{ml})$ which indicates that the methanol extract of $C$. asiaticum bulb has high pharmacological actions ${ }^{26}$. It also indicates that the plant might have the potentiality to kill cancer cells ${ }^{27}$.

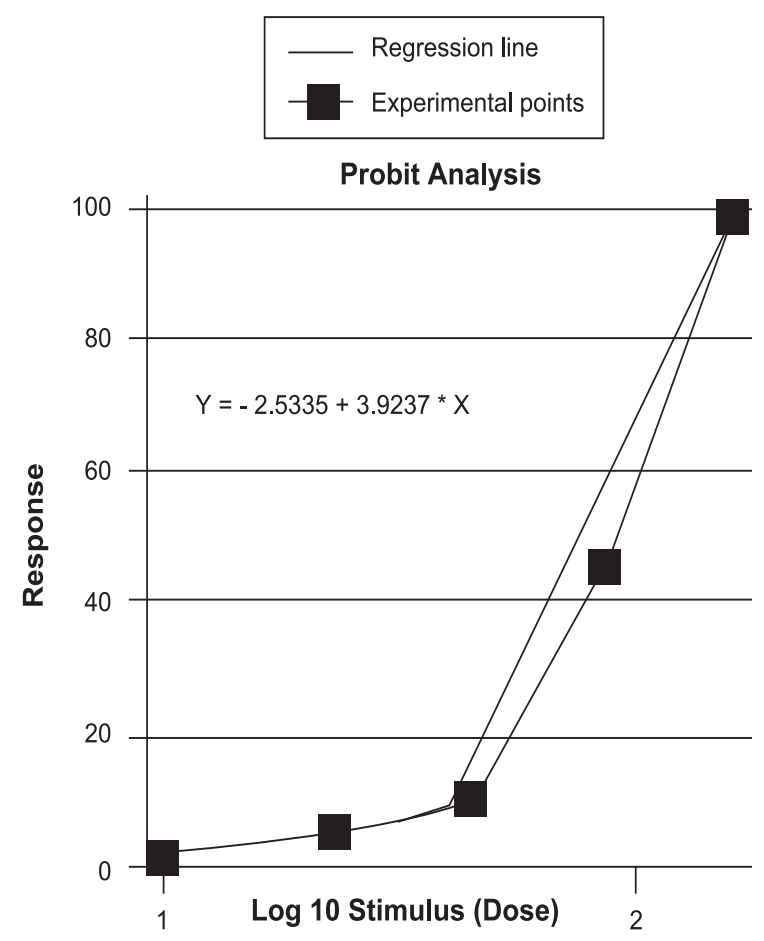

Figure 2. Regression line for determining the $L C_{50}$ value of methanol extract of Crinum asiaticum bulb 
The results of the study demonstrate that the methanol extract of C. asiaticum bulb exhibits very potential antibacterial effect in experimental models which support the claims by traditional medicine practitioners. On the basis of the results, it can be used as a good source of microbiological references although principle compounds responsible for such action are unknown. However, further studies are still necessary to verify the above results in other experimental models to conclude whether the effect observed is truly authentic for aforementioned effect. Phytochemical investigation is also proposed in order to isolate the active fraction and to explore their individual action in regard of the above functions.

\section{References}

1. Ghani A. 1998. Medicinal Plants of Bangladesh: Chemical Constituents and Uses. (Asiatic Society of Bangladesh, Dhaka). pp 142-143 and 334-337.

2. Zhanhe J and Alan WM. 2000. Amaryllidaceae. In: Flora of China, Vol. 24, pp. 264. Science Press (Beijing) and Missouri Botanical Garden Press.

3. Walter CH. 1998. Crinum asiaticum. In: Flora of North America, Vol. 26, pp. 55, 278, 279. Oxford University Press.

4. Bauer AW, Kirby WMM, Sherris JC and Turck M. 1966. Antibiotic susceptibility testing by a standardized single disc method. Am J Clin Pathol. 45(4):493-96.

5. Thornsberry C, Barry AL, Jones RN, Baker CN and Badal RE. 1982. Tentative interpretive standards for agar disk diffusion antimicrobial susceptibility testing of cefoperazone. J Clin Microbiol. 15 (5):769776.

6. Braca AT, Nunziatina DB, Lorenzo Di, Pizza C, Politi M \& Morelli I. 2001. Antioxidant principles from Bauhinia terapotensis. $J$ Nat Prod. 64: 892-895.

7. Oke JM and Hamburger MO. 2002. Screening of some Nigerian medicinal plants for antioxidant activity using 2,2-diphenyl-picrylhydrazyl radical. African J Biomed Res. 5: 77-79.

8. Meyer BN, Ferrigni NR, Putnam JE, Jacobson LB, Nichols DE and McLaughlin JL. 1982. Brine shrimp: a convenient general bioassay for active plant constituents. Planta Medica. 45 (1):31-34.

9. Persoone G, Sorgeloos P, Roels O and Jaspers E. (Eds). 1980. The brine shrimp Artemia. Proceeding of the International Symposium on the Brine Shrimp Artemia salina. Vol.1-3, 1979 Aug 20-23; Texas, USA, Universa Press, Witteren, Belgium.

10. Ciulei I. 1981. Methodology for the analysis of Vegetable Drugs. Chemical industries Branch, Division of Industrial operations. UNIDO Romania: 24, 26 and 67. pp17-25.

11. Sofowora AA. 1993. Medicinal plants and Traditional Medicines in Africa. 2nd edition, pp 81-85, Spectrum Books Ltd., Ibadan, Nigeria.
12. Sankar KD, Debdulal B, Sourav C and Krishnendu BK. 2010. Antimicrobial activities of some medicinal plants of West Bengal. International Journal of Pharma and Bio Sciences. 1(3):1-10.

13. Dwivedi S. 2007. Terminalia arjuna Wight and Arn.- a useful drug for cardiovascular disorders. J Ethnopharmacol. 114 (2):114-29. 12

14. Sanches NR, Cortez DAG, Schiavini MS, Nakamura CV and Dias Filho BP. 2005. An Evaluation of Antibacterial Activities of Psidium guajava (L.). Braz. Arch Biol Tech An Int Jr. 48 (3): 429-436.

15. Scalbert A. 1991. Antimicrobial properties of tannins. Phytochemistry. 30: $3875-3883$

16. Sawer IK, Berry MI, Ford JL, 2005. The killing effect on Staphylococcus aureus. Lett Appl Microbiol. 40: 24-29.

17. Bonjean K, De Pauw-Gillet MC, Defresne MP, Colson P, Houssier C, Dassonneville L, Bailly C, Greimers R, Wright C, Quentin-Leclercq J, Tits M and Angenot L.1998. The DNA intercalating alkaloid cryptolepine interferes with topoisomerase II and inhibits the primarily DNA synthesis in B16 melanoma cells. Biochemistry. 37: 5136-5146.

18. Cohen ML. 1992. Epidemiology of drug resistance: implications for a post- antimicrobial era. Science. 257 (5073):1050-1055.

19. Sun Q, Shen YH, Tian JM, Tang J, Su J, Liu RH, Li HL, Xu XK and Zhang WD. 2009. Chemical constituents of Crinum asiaticum L. var. sinicum Baker and their cytotoxic activities. Chem Biodivers. 6(10):1751-7.

20. Koleva II, Van Beek TA, Linssen JPH, de Groot A and Evstatieva LN. 2002. Screening of plant extracts for antioxidant activity: a comparative study on three testing methods. Phytochemical Analysis. 13 (1): 8-17.

21. Sadhu SK, Okuyama E, Fujimoto H and Ishibashi M. 2003. Separation of Leucas aspera, a medicinal plant of Bangladesh, guided by prostaglandin inhibitory and antioxidant activities. Chemical Pharmaceutical Bulletin (Tokyo). 51(5): 595-98.

22. Ramarathnam N, Ochi H and Takeuchi M. 1997. Antioxidant Defense System in Vegetable Extracts. In: Natural Antioxidants: Chemistry, Health Effects and Applications, Ed Shahidi F, AOCS Press: Champaign, Illinois, pp. 76-87.

23. Velioglu YS, Mazza G, Gao L and Oomah BD. 1998. Antioxidant activity and total phenolics in selected fruits, vegetables grain products. J Agric Food Chem. 46 (10): 4113-4117.

24. Rice-Evans CA, Miller NJ, Bolwell PG, Bramley PM and Pridham JB. 1995. The relative antioxidant activities of plant derived polyphenolics flavonoids. Free radical Res. 22 (4):375-383.

25. MacLaughin JL, Chnag CJ and Smith DL. 1991. Bench-Top Bioassays for the discovery of Bioactive Natural Product: An update (Atta UrRahman Ed), Studies in natural product Chemistry. Elsevier Science Publisher B.V. Amsterdam. 9:101-103.

26. Gupta SS. 1994. Prospects and perspectives of natural plants products in medicine Indian J Pharmacol. 26 (1): 1-12.

27. Mc Laughlin JL, Roger LL and Anderson JE. 1998. The use of biological assays to evaluate botanicals. Drug Information J. 32: 513-524. 